\title{
The road ahead for research in Greece
}

\author{
Underfunding, chronic structural deficiencies and lack of proper evaluation are acutely harming Greek \\ science. The only way forward is to increase investment in human capital and infrastructure, coupled \\ with organizational reforms and a change of government attitude towards research.
}

The effects that the recent financial crisis has had on the Greek economy and society are devastating. With official unemployment close to $27 \%$ (ref. 1), youth unemployment exceeding $60 \%$ (ref. 2), thousands in the private sector losing their jobs every day and no recovery yet, Greece has probably suffered more than any other European country. Six successive years of recession, which shrunk the country's gross domestic product (GDP) by more than $20 \%$ since $2007^{3}$, have been enough to strangle almost every economic activity, and to even lead to the rise of political extremism - unheard of in modern Greek society and political history.

In these circumstances, Greek science has recurrently been sending emergency signals - but whether decision makers have been willing to respond favourably isn't clear. With budgets and salaries cut by up to $50 \%$ across the board since 2009 , university mergers that do not seem to work and were mostly implemented at the request of the foreign lenders, and with an estimated more than 150,000 Greek scientists living and working abroad ${ }^{4}$ (about 30,000 more than in 2010), the current state of resources within Greece are inadequate. As a matter of fact, many scientists are now strenuously warning about the acuteness of the situation ${ }^{4,5}$. And although this critical condition is by now well appreciated by the international scientific community, preserving or let alone boosting the scientific research output of the country doesn't seem to be among the top priorities of the Greek government.

Vigorous, well-funded research activity and infrastructure are the bedrock for long-term innovation and economic growth. Unfortunately too often, government policies are short-sighted and neglect the fact that the competitiveness of a longunderfunded scientific enterprise may take decades to restore. In an Interview on page 686 of this issue, Eleftherios Economou, from the Foundation for Research and Technology Hellas (FORTH) - one of Greece's most successful research institutes - describes the painstaking effort it took, during the early 1980s, to create this organization ${ }^{6}$. Without the few remaining pockets of funding, mainly from the European Union (EU) through so-called

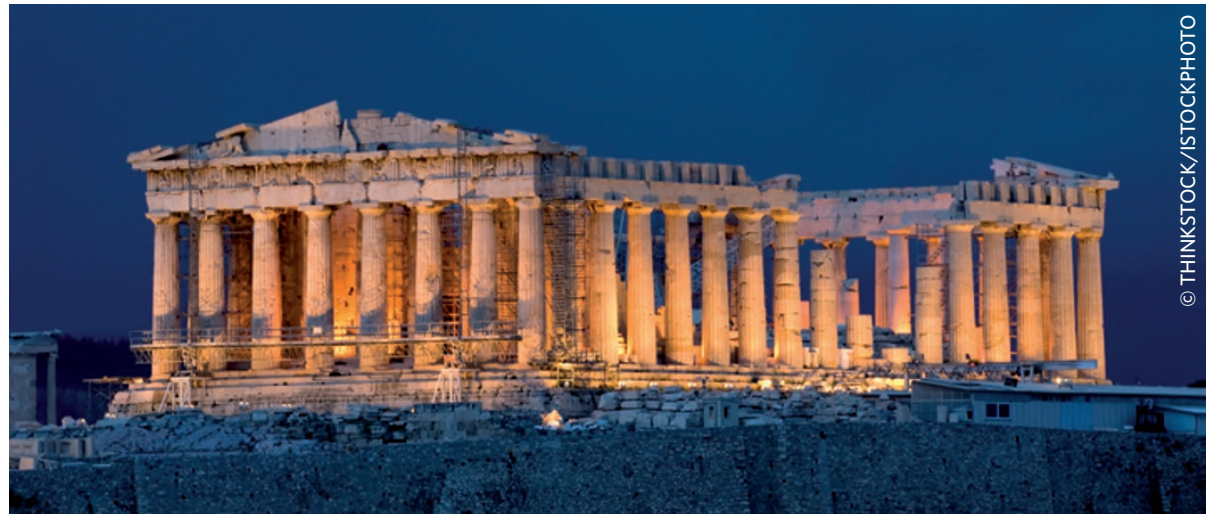

Greek science has paid a hefty price during the recent economic crisis. To regain its momentum it should be spared from austerity and be open to deep reforms.

structural funds, continued austerity-led cuts and brain drain may threaten the very existence of the remaining internationally competitive groups in Greece. Greek science is undeniably in a critical condition, and a coordinated action by government, academia and industry is urgently needed to reverse this descent.

In a Commentary on page 683, Costas Soukoulis of Iowa State University and FORTH argues that even amidst this crisis Greece's research system still shows signs of excellence compared with those of fellow European countries, for example, in terms of securing funding from European research grants and the country's contribution to the top $1 \%$ most-cited papers in the world ${ }^{7}$. This resilience of the scientific output in the tough economic environment is, among other factors, founded on the traditionally large percentage (above $80 \%$ ) of Greek students that decide to pursue university education 7 , thus forming a strong base for scientific research and development.

The way forward should begin first with the establishment of rigorous and rational evaluation of the Greek universities and their staff. Without this it is difficult to imagine how the limited resources could be fairly distributed on merit and how worthy groups and individuals could survive and grow. Second, a systematic restructuring should be implemented to reduce the large number of universities and other research institutions. Third, the funding for research and development in Greece, which at the moment is only around $0.6 \%$ of the GDP (ref. 7), should at least match the level of research funding in other EU countries, particularly during this crisis. Increasing the level of research and development funding to European standards and modernizing the research infrastructure are vitally needed. Also, to reverse the brain drain and encourage Greek scientists working abroad to return, independent recruitment committees that are encouraged to use objective and measurable criteria following international standards should be established.

Greece is not the only country in Europe going through difficulties, but the government must ensure that science is spared from austerity ${ }^{8}$. To save Greek science from languishing and bring it up to the most advanced level of European science, the Greek government should take a number of bold yet important steps towards a path of deep reform.

\footnotetext{
References

1. Greek Q1 unemployment climbs to 27.4 pct. Reuters (13 June 2013); available via http://go.nature.com/fgNvDy

2. Greece's young: Dreams on hold as fight for jobs looms. $B B C$ (30 May 2013); http://www.bbc.co.uk/news/business-22702003

3. Daring to hope, fearing to fail. The Economist (4 May 2013); available via http://go.nature.com $/ \mathrm{qFCNbF}$

4. Nature 496, 271 (2013)

5. Nature $\mathbf{4 7 5}, 13(2011)$

6. Economou, E. Nature Mater. 12, 686-687 (2013).

7. Soukoulis, C. Nature Mater. 12, 683-685 (2013).

8. Nature Mater. 12, 377 (2013).
} 